\title{
O COMBATE MÉDICO AO ALCOOLISMO NO BRASIL DO SÉCULO XIX
}

Alisson Eugenio ${ }^{1}$

Sabe-se que a medicina se consolidou, após a "era das revoluções", como um dos mais prestigiados campos de conhecimento, uma vez que, desde a geração de Bacon e Descartes, a saúde começou, com a valorização do corpo e da individualidade, a ser compreendida nos meios mais cultos como um dos mais importantes bens dos indivíduos, um dos mais fortes fundamentos da felicidade dos povos e uma das mais sólidas bases do progresso. A partir de então, tal saber vem experimentando, principalmente depois das descobertas da geração de Pauster na área da microbiologia (os patógenos, por exemplo), sucessivos avanços que têm permitido os seus profissionais expandiram o horizonte da aplicação dos seus estudos.

Essa expansão começa a ganhar maior impulso com Iluminismo. Seus mais influentes protagonistas argumentaram a favor da necessidade de o saber ser mais pragmático, isto é, que também pudesse produzir conhecimento capaz de melhorar a condição humana e mitigar os sofrimentos da humanidade. A medicina foi um dos campos científicos cujas elites profissionais mais se identificaram com tal argumentação. Mais do que isso, sustentaram grande parte da justificação da sua institucionalização e da sua aproximação ao Estado nesse argumento iluminista.

Enquanto promoviam seu saber apresentando-o como um instrumento privilegiado de melhoria das condições sanitárias dos povos, o que para isso precisaram ampliar a capacidade de ele resolver os principais problemas de saúde da população, diversos intelectuais médicos afinados com o pragmatismo do saber defendido pelos iluministas atribuíram-se a missão de melhorar a situação da saúde pública nas sociedades em que atuavam.

A sociedade brasileira foi uma delas. A tradução de um tratado de medicina prática, especializado em doenças de escravos, do cirurgião francês Jean Barthelemy Dazille, feita pelo cirurgião português Antônio José Vieira de Carvalho que atuava em Minas Gerais, e publicada sob o patrocínio régio em $1801,^{2}$ é um exemplo do esforço médico ilustrado para colocar o seu saber ao serviço das necessidades da vida cotidiana. Afinal, a referida obra, que faz parte de um conjunto de demais publicações e outros esforços do "despotismo esclarecido" português para adaptar Portugal às novas exigências econômicas e humanitárias da época, trata-se de um manual didático no qual os senhores poderiam se orientar para prevenir e curar as doenças de seus escravos. Quando ela foi impressa, havia ainda poucos médicos no Brasil, pois não havia cursos superiores na Colônia, o que tornava a comunidade médica nesta parte do império lusitano uma categoria intelectual rarefeita, limitando assim a produção de propostas e a visibilidade do seu incipiente ideário reformista médico.

\footnotetext{
${ }^{1}$ Professor de História Moderna na Universidade Federal de Alfenas (Brasil). E-mail: <alissoneugenio@ yahoo.com.br>.

2 DAZILLE, Jean Barthelemy. Observações sobre as enfermidades dos negros. Lisboa: Arco do Cego, 1801.
} 
Porém, partir de 1808, com a chegada de diversos médicos junto com a comitiva da família real e a criação da Escola Anatômica, Cirurgia e Médica de Salvador e a do Rio de Janeiro no mesmo ano, posteriormente, em 1815, elevadas ao status de academia médico-cirúrgica e, entre 1828 e 1832, reestruturadas para serem transformadas nas duas primeiras faculdades de medicina brasileiras, aos poucos uma elite médica foi sendo formada entre nós. Trata-se de profissionais que obtiveram êxito na sua área de atuação, tanto na esfera funcional, ocupando importantes cargos, quanto na esfera intelectual, escrevendo sobre assuntos do seu campo de conhecimento. ${ }^{3}$ Isso porque eles se enquadram em pelo menos uma dessas esferas, ao terem se associado em sociedades científicas, como a Academia Imperial de Medicina, lecionado nas faculdades de medicina, chefiado instituições médicas, como o Hospício de Pedro II, integrado comissões de órgãos de controle na área de saúde, como a Junta de Higiene Pública, assumido postos políticos ligados a essa mesma área, como as Inspetorias de Saúde das províncias e as Delegacias de Higiene nos municípios, colaborado com periódicos médicos, escrito livros e elaborado relatórios sobre as condições sanitárias do país.

Apesar da diversidade dos indivíduos desse grupo (uma vez que falavam de lugares e tempos diferentes), eles se identificavam a partir dos seus interesses corporativos em comum (o de, principalmente, aproximar a medicina do Estado), da sua luta para melhorar as condições de saúde da população e da sua assimilação da idéia de progresso, que foi usada por eles para embasar as suas propostas. Por essa razão, a expressão elite médica, que longe de denotar uma homogeneidade absoluta entre os seus membros, será usada neste texto como sinônimo de "comunidade epistemológica", quer dizer, profissionais responsáveis pelas "unidades fundamentais que constroem o conhecimento e conduzem sua difusão por certos canais". ${ }^{4}$

Com ela foram surgindo entidades médicas e seus periódicos que atuavam como meio de debate acadêmico e de divulgação de conhecimentos que poderiam ser úteis ao público em geral. Mais do que isso, com a abertura da Imprensa Régia e a possibilidade de publicação de livros e jornais, bem como com a criação da Academia Imperial de Medicina, que reforça a institucionalização do saber médico no Brasil, a elite médica encontrou meios para divulgação de medidas, segundo ela, necessárias para reduzir os altos índices de mortalidade no país. Eis o que propuseram: 1) aos grandes proprietários rurais: ter mais cuidado com a alimentação, vestimenta, moradia, carga de trabalho, repouso, costumes e tratamento das doenças dos seus escravos; 2) à população em geral: parar de despejar sujeira nas ruas; aceitar o deslocamento dos sepultamentos para fora do perímetro urbano; ter maior asseio com o corpo; ser mais cautelosa com as gestantes e os recém-nascidos; alugar amas-deleite somente quando fosse necessário; vacinar-se contra a varíola; e contratar profissionais da medicina, e não os práticos (barbeiros, parteiras e curandeiros), para a prestação de serviços de saúde; 3) ao Estado: promover o asseio público, criar leis contrárias ao sepultamento e à criação $e$ ao abate de reses nas áreas urbanas; fiscalizar o comércio de alimentos; controlar por meio de regulamentos o aluguel de

\footnotetext{
${ }^{3}$ Essa definição foi elaborada com base na exposição feita por NETO, André de Faria P. Ser médico no Brasil. Rio de Janeiro: Fiocruz, 2001, p. 32-33.

${ }^{4}$ BURKE, Peter. Uma história social do conhecimento: de Gutenberg a Diderot. Rio de Janeiro: Jorge Zahar, 2003, p. 17.
} 
amas-de-leite e a prostituição; promover a vacina contra a varíola, estimulando a sua aceitação pela população; destinar maior número de agentes de saúde, e prepará-los devidamente para fazer o serviço de vacinação; ampliar a oferta de serviços hospitalares, e melhorar a sua qualidade; acabar com a importação de africanos; e reprimir o exercício da profissão médica sem formação acadêmica, tornando-o crime contra a saúde pública.

Em conjunto, essas medidas integram um ideário reformista, o qual, entre outras estratégias, procurou combater alguns costumes que seus idealizadores começaram, com o avanço da medicina sanitarista, a perceber como prejudiciais à saúde pública. ${ }^{5}$ Muito já foi investigado sobre esses temas. No entanto, falta esclarecer a visão médica sobre algumas práticas ainda pouco estudadas em nosso país, como o consumo em excesso de bebidas alcoólicas.

Por isso, a seguir serão analisadas as bases ou tradições intelectuais sobre as quais os autores dos textos médicos dedicados ao alcoolismo sustentaram as suas teses sobre a necessidade da sociedade, com o apoio do Estado, combater tal "doença social". Em outras palavras, buscar-se-á analisar a estrutura intelectual dos discursos médicos sobre hábitos que, com os impactos da Era das Luzes na medicina e na vida cotidiana, começaram a ser questionados e transformados em alvo das críticas médicas.

Mirando-se nesses objetivos, deve-se perguntar: quais os principais argumentos os médicos que pesquisaram os efeitos do álcool no organismo humano e na sociedade usaram para condenar o consumo cotidiano e em excesso das bebidas alcoólicas? E em quais conceitos e tradições intelectuais eles se apoiaram para fundamentar sua condenação? De que maneira os seus argumentos contribuíram para a construção da percepção de que a sua ingestão habitual e excessiva é uma doença que deve ser combatida?

No Brasil, desde pelo menos o início da segunda metade do século XIX, membros da elite médica mostravam-se preocupados com os efeitos do álcool no organismo, ${ }^{6}$ ao escrever textos sobre esse assunto usando conceitos centrais do Iluminismo, como o de progresso, para embasar seus argumentos que levaram o consumo excessivo e rotineiro de bebidas alcoólicas a ser considerado como uma doença: o alcoolismo. Trata-se de um entre outros alvos do repertório de costumes selecionados pelas elites médicas para ser combatido pelo seu ideário reformista.

Tal ideário foi expresso em diversos textos, os quais serão abordados neste trabalho como uma forma de ação no meio social, porque tentaram por meio deles mostrar a necessidade de se confrontar determinadas práticas sociais, tanto no âmbito público, quanto no privado, alegando que elas causavam sérios danos à saúde da população e, por isso, obstavam o progresso do país. Para interpretá-los dessa maneira, dois conceitos serão essenciais. O primeiro é o conceito de cultura apresentado por Peter Burke, "um sistema de significados, atitudes e valores compartilhados", 7 que permitirá compreender como, por meio das suas propostas, os

\footnotetext{
${ }^{5}$ EUGÊNIO, Alisson. Arautos do progresso: ideário médico sobre saúde pública no Brasil da época do Império. São Paulo: Edusc, 2012.

${ }^{6}$ SANTOS, Fernando Sérgio Dumas dos. Alcoolismo: a invenção de uma doença. Campinas, Dissertação de mestrado em história, Unicamp, 1995.

${ }^{7}$ BURKE, Peter. Cultura popular na Idade Moderna. São Paulo: Cia. das Letras, 1995, p. 21.
} 
médicos, visando melhorar as condições sanitárias no Brasil do século XIX, defenderam a importância da reforma de alguns hábitos culturais, há séculos arraigados na sociedade, considerados por eles prejudiciais à saúde.

Para isso, basearam-se em uma nova forma de concepção da medicina, das causas das doenças e dos meios de combatê-las legada pela Ilustração, qual seja, a de que as descobertas médicas não são resultantes da revelação divina, e sim da razão e da experiência, as doenças não são provocadas por forças sobrenaturais, e sim por fatores sociais e naturais, e a solução delas não é uma graça de Deus, e sim fruto da inteligência humana. ${ }^{8}$ Ao partirem dessa concepção, os médicos que escreveram sobre os problemas de saúde da população brasileira no período em tela fizeram grande esforço para explicar que a solução deles dependeria, em boa parte, de mudanças de valores e atitudes da sociedade e do empenho do Estado para promover políticas públicas de caráter preventivo.

O segundo conceito é o de campo apresentado por Pierre Bourdieu, "o universo no qual estão inseridos os agentes $e$ as instituições que produzem, reproduzem ou difundem a arte, a literatura ou a ciência". ${ }^{9}$ Pois, é a partir desse universo, locus institucional que serve de base estratégica para legitimação de idéias e interesses, que os autores constroem, sustentam e fazem "imposições, solicitações, etc." que, apesar de serem "relativamente independentes das pressões do mundo social", sofrem a sua influência. Quer dizer, mesmo sendo parcialmente autônomas, são frutos de demandas provocadas por problemas da vida cotidiana, às quais visam responder. ${ }^{10}$

No caso desse trabalho, as imposições e solicitações são as propostas médicas de combate ao alcoolismo no Brasil do século XIX. Os seus autores são os profissionais que estavam vinculados a instituições médicas (academias, faculdades, hospitais, etc.), colaboravam para os periódicos médicos, prestavam serviço de observação da situação sanitária nos municípios e escreviam livros destinados ao público leigo em matéria de saúde. E o campo em que atuavam é a medicina, a partir do qual legitimaram as suas proposições.

Para legitimá-las, muito contribuiu a ideia de progresso como ferramenta intelectual de interpretação do mundo. Isso porque, à medida que ela foi convertida após a llustração em uma nova ideologia, a "ideologia do progresso", baseada, conforme explicou Gilberto Dupas, "na primazia da ciência e da técnica" ${ }^{11}$ foi usada pelos médicos para dar credibilidade às suas propostas como se elas fossem produtos da razão científica, e por isso dotadas de verdades apriorísticas, ou seja, autoevidentes ou pré-estabelecidas.

A assimilação dessa ideia por grande parte dos médicos, bem como outros profissionais de demais campos, pode ser explicada pelo deslocamento que vinha ocorrendo desde o século XVIII da transcendência para imanência como foco das

\footnotetext{
${ }^{8}$ As transformações do saber médico que permitiram o surgimento dessa nova forma de concepção foram estudas por GUSDORF, Georges. Dieu, la nature, l'homme au siécle des lumiéres. Paris: Payot, e é com base no seu trabalho que essas afirmações foram feitas.

${ }^{9}$ BOURDIEU, Pierre. Os usos sociais da ciência. São Paulo: Ed. Unesp, 2004, p. 20.

${ }^{10}$ BOURDIEU, Os usos sociais da ciência..., p. 21 e BOURDIEU, Pierre. "Campo de poder, campo intelectual e habitus de classe”. In: A economia das trocas simbólicas. São Paulo: Perspectiva, 2001, p. 190.

${ }^{11}$ DUPAS, Gilberto. O Mito do progresso. São Paulo: Unesp, 2006, p. 23.
} 
atenções e esforços humanos, do qual a preocupação com a saúde pública é um exemplo. ${ }^{12}$ Dessa maneira, a ideia de progresso está evidenciada nos textos médicos, que servirão como fonte deste estudo, indicando a defesa pelos seus autores do uso da ciência e da técnica como instrumentos de intervenção no mundo para a solução de problemas da vida cotidiana, entre os quais os de saúde pública.

Defesa essa que encontrou em tal ideia a justificativa para que as proposições médicas destinadas à luta contra o alcoolismo na sociedade brasileira do século XIX fossem apresentadas pelos seus formuladores como um apriore científico, com o objetivo de torná-las legítimas para que pudessem ser aceitas pelos seus destinatários $e$, com efeito, atingissem a finalidade para qual foram elaboradas. Enfim, os médicos que se empenharam nessa luta apoiaram-se no conceito de progresso, visando legitimar, como produto da razão científica, os argumentos inseridos nos seus textos dedicados à explicação de como a situação da saúde pública poderia ser melhorada.

Por essa razão, a idéia de progresso é fundamental para a compreensão de propostas de mudanças culturais defendidas em tal época por profissionais baseados nos seus campos de atuação, uma vez que ela marcou a forma deles interpretarem o mundo e os problemas da vida cotidiana. No caso dos médicos, além disso, ela lhes serviu como base intelectual para eles sustentarem o argumento de que o seu saber é fundamental para a sociedade moderna, o que os aproximaram do Estado, os tornando um dos principais agentes reformistas da cidade e dos hábitos dos seus habitantes, e contribuiu para a estruturação da medicina, como no Brasil a partir do século XIX.

Dessa forma, como o pensamento científico foi influenciado por tal idéia, as proposições contidas nos textos de medicina, para desestimularem o consumo de bebidas alcoólicas em excesso na sociedade brasileira oitocentista, podem ser interpretadas, por meio do conceito de cultura e o de campo, como expressão da assimilação da ideologia do progresso ${ }^{13}$ pela elite médica desde, pelo menos, 1808. Sendo, pois, a partir dela que tal elite justificou, seguindo a tendência ocidental em curso desde a Ilustração, o combate a algumas práticas sociais por ela consideradas prejudiciais à saúde, como um ponto de partida para o avanço social e econômico do país.

Com base nessa interpretação, será mostrado que os médicos engajados nesse combate se atribuíram a missão de contribuir com tal avanço, propondo modificações na vida cultural da sociedade em que atuavam para melhorar a sua situação sanitária, com o argumento de que a saúde é base do progresso e, por isso, deveria ser transformada em objeto permanente de políticas governamentais. Assim, colaboraram para que o alcoolismo fosse visto como doença social e, como tal, deveria ser inserido

\footnotetext{
${ }^{12}$ FALCON, Francisco José Calazans. A época pombalina: política econômica e monarquia ilustrada. São Paulo: Ática, 1982, p. 119.

${ }^{13}$ Essa expressão foi usada por DUPAS, O Mito do progresso..., p. 23 para explicar ao longo do seu livro que a idéia de progresso foi transformada em ideologia para sustentar opções políticas da elite intelectual e governamental no Ocidente a partir da Ilustração, usando para isso o conceito de ideologia ("visões sintéticas e fragmentárias, elípticas, coerentes na aparência, que engendram o sentido social da ação") formulado por Raymondo Mier no seu texto homônimo, dedicado a tal conceito, inserido na obra, organizada por Laura Baça Bokserliwerant et al, intitulada Léxico de la poítica. Ciudad del México, Facultad Latinoamericana de Ciencias Sociais, 2000, p. 323.
} 
no conjunto dos problemas de saúde a serem combatidos para viabilizar a marcha do progresso no país.

Sendo assim, a seguir serão analisadas as bases ou tradições intelectuais sobre as quais os autores dos textos médicos dedicados ao alcoolismo sustentaram as suas teses sobre a necessidade da sociedade, com o apoio do Estado, combater tal "doença social". Em outras palavras, buscar-se-á analisar a estrutura intelectual dos discursos médicos sobre hábitos que, com os impactos da Era das Luzes na medicina $e$ na vida cotidiana, começaram a ser questionados pelas elites médicas $e$ transformados em alvo de seu ideário reformista.

Há uma quantidade considerável de pesquisas sobre esse tema no mundo, cujas referências mais importantes serão utilizadas ao longo deste texto. Uma delas merece destaque por ser tratar de uma pesquisa dedicada, tal como a que aqui apresento, à experiência histórica brasileira do século XIX. Trata-se da dissertação em História de Fernando Sérgio Dumas dos Santos intitulada Alcoolismo: a invenção de uma doença, concluída na Unicamp em 1995.

Sabe-se o quanto é recente a construção do campo de estudos historiográficos dedicado à doença, medicina e saúde no Brasil. Quando a pesquisa acima citada foi concluída, ele ainda estava em formação, razão pela qual não havia até então uma tradição entre nós em estudar objetos abrigados por essa tríade temática. Entretanto, duas décadas depois, essa realidade foi modificada, podendo se afirmar com segurança que o referido campo está consolidado e dispõe de uma produção abundante e profícua.

Em relação ao alcoolismo não se pode dizer o mesmo, pois além do estudo de Fernando dos Santos quase mais nada foi produzido sobre esse tema a respeito do Brasil do século XIX, época em que o hábito de ingerir bebidas alcoólicas rotineira e exageradamente passou a ser considerado uma doença. A contribuição do estudo de Fernando dos Santos para a compreensão do processo histórico de transformação de um costume tolerado para outro de natureza sanitária é enorme. Em primeiro lugar isso se deve ao seu caráter inaugural e único até hoje. Segundo porque, apoiado em pesquisas sobre o mesmo objeto dedicadas a realidades diferentes (EUA, Europa e América Latina), revela que no Brasil uma nova forma de percepção de tal hábito estava em curso, usando sobretudo as teses da Faculdade de Medicina do Rio de Janeiro (FMRJ). Segundo ele: "As mudanças ocorridas em relação ao uso das bebidas alcoólicas nas sociedades ocidentais caracterizam a invenção de novas tradições de uso, disciplinarizadas segunda a lógica das sociedades em que se geraram". ${ }^{14}$ No ocidente, as sociedades estavam cada vez mais sendo marcadas pela lógica do capitalismo industrial, o qual se consolidava exigindo novos padrões de comportamento das classes populares, entre eles o do controle da bebedeira, visando à preservação da ordem pública e da saúde dos indivíduos, cujos corpos deveriam se adaptar aos novos ritmos da produção.

Dessa maneira, valendo-se da análise de Eric Hobsbawn sobre a "invenção das tradições" e do conceito de disciplina nas relações do "poder microfísico", Fernando dos Santos sustenta que o mesmo fenômeno observado em diferentes regiões ocidentais, à medida que o capitalismo se consolidava, o da transformação do

\footnotetext{
${ }^{14}$ SANTOS, Alcoolismo: a invenção de uma doença..., p. 7.
} 
consumo freqüente e demasiado de bebidas alcoólicas em doença, também foi vivenciado no Brasil, graças à atuação inicialmente de médicos que assimilaram obras de influentes intelectuais da medicina estrangeira, especialmente a francesa, alemã e norteamericana, e posteriormente com a adesão de políticos e outras categorias capazes de influenciar a opinião pública. Eis, em síntese a sua tese.

Em 2010, o mesmo autor revisitou o tema procurando aprofundar uma questão por ele ensaiada em sua antiga dissertação em 1995, qual seja: a relação entre psiquiatria e alcoolismo, mostrando como textos produzidos entre o final do século $\mathrm{XIX} e$ as décadas iniciais do século XX por psiquiatras abordaram a responsabilidade do álcool sobre a loucura, tomando como um dos exemplos mais emblemáticos a internação de Lima Barreto. ${ }^{15}$

Seguindo essa mesma linha, em 2015 Marianne Azevedo Bulhões estudou como os diagnósticos médicos de alcoolismo acabaram afetando a identidade e a vida cotidiana dos indivíduos portadores dessa "doença", usando também o famoso caso de Lima Barreto, que acabou sendo internado em um Hospital psiquiátrico como portador de loucura originada de alcoolismo. ${ }^{16}$

O que eu pretendo fazer é mostrar que a luta contra o alcoolismo faz parte de um conjunto maior de alvos, escolhidos pelas elites médicas atuantes no Brasil do século $\mathrm{XIX}$, a serem enfrentados como entraves ao progresso nacional, por se tratarem (na opinião delas) de hábitos danosos à saúde pública. Além disso, mostrarei também que a principal base intelectual utilizada pelos autores dos textos que se dedicaram a esse assunto foi constituída a partir do legado conceitual ilustrado, principalmente o conceito de progresso, que serviu como forma de legitimação do seu discurso reformista contra os males da saúde pública, particularmente o consumo em excesso e rotineiro de bebidas alcoólicas.

Em estudo anterior mostrei que as elites médicas que atuaram no Brasil na época do Império, seguindo a tendência dos seus pares ocidentais, construíram um ideário reformista para melhorar as condições de saúde do país. ${ }^{17}$ Ao vasculhar a documentação médica, principalmente as teses da Faculdade de Medicina, à procura de dados sobre o referido ideário, o tema do alcoolismo apareceu recorrentemente. Como não tinha mais tempo para incorporar na tese (devido à urgência do prazo final para defesa), guardei as informações obtidas para usar em outra oportunidade. Recentemente, em um debate sobre uso de drogas, soube que a taxa de óbito por causa do alcoolismo aumentou entre 1996 e 2010, conforme dados do DATA-SUS, ${ }^{18}$ o que me redespertou o interesse de retornar aos escritos médicos da época do Império para investigar os argumentos dos críticos ao consumo regular e exagerado de bebidas alcoólicas.

\footnotetext{
${ }^{15}$ SANTOS, Fernando Sergio Dumas dos; VERANI, Ana Carolina. "Alcoolismo e medicina psiquiátrica no Brasil no início do século XX". História, Ciências, Saúde - Manguinhos, Rio de Janeiro, vol. 17, dez. 2010, p. 401420.

${ }^{16}$ BULHÕES, Marianne. Azevedo cheio de mistério e cercado de mistérios: Lima Barreto (1881-1922), psiquiátras, hospício, e o diagnóstico de alcoolismo. Rio de Janeiro, Dissertação de mestrado em História da Ciência, Fundação Oswaldo Cruz, 2015.

${ }^{17}$ EUGÊNIO, Arautos do progresso...

${ }^{18}$ De 2,8 por 100 mil para 5,2 por 100 mil. www.datasus.saude.gov.br
} 
Em primeiro lugar é necessário definir alcoolismo como "uma moléstia de evolução ordinariamente lenta e progressiva causada pelo abuso de bebidas espirituosas", isto é, "a ingestão quase diária e repetida de bebidas alcoólicas, tomadas em quantidade exagerada," principalmente "a aguardente e as bebidas cuja riqueza de álcool é de 40 a $60 \%$ ". ${ }^{19}$

Benjamin Rush foi primeiro autor a abordar esse tema na obra Inquiry into effects oh ardent spirits upon the human body and mind publicada em 1785 e reeditada diversas vezes ao longo do século XIX. ${ }^{20}$ Esse médico é considerado um dos maiores expoentes do Iluminismo norteamericano, pois, além de ter sido um dos mais destacados promotores do avanço da medicina em seu país, também participou do Congresso Continental, assinou a Declaração de Independência, opôs-se à escravidão e defendeu a educação para as mulheres. Baseado na anatomia patológica procurou explicar os efeitos do álcool no corpo e na mente dos indivíduos que se entregavam à "drunkenness" (bebedeira), a qual chamou de "odious disease" (doença odiosa).

No entanto, foi médico sueco Magnus Huss, em 1849, que cunhou o termo alcoolismo na obra Alcoolismo crônico ou doença alcoólica crônica, a partir da qual classificou tal doença como uma das mais sérias ameaças à saúde pública e, com isso, chamou a atenção para os problemas por ela causados. Essa obra acabou influenciando as demais que lhe seguiram, ao substituir o antigo termo bebedeira por um conceito novo que permitiu o estabelecimento e a classificação taxionômica de uma nova enfermidade. ${ }^{21}$

Essas obras, entre outras dedicadas ao mesmo assunto, tornarem-se referências fundamentais para a compreensão do alcoolismo não somente como uma doença, mas também como "um mal social," porque, para grande parte dos médicos que assimilaram aquele conceito, por exemplo, José Simplício Monteiro Braga, para quem, por isso, ele "deve ser considerado um dos maiores flagelos da humanidade". ${ }^{22}$

Aquelas obras, à medida que foram sendo divulgadas pelos periódicos médicos, acabaram sendo assimiladas pela comunidade médica nacional, o que gerou também entre nós uma nova percepção sobre um antigo costume, agora classificado como doença. Enquanto essa assimilação ocorria, foi se formando na época a opinião, primeiro entre os médicos, depois entre políticos e demais indivíduos atentos à vida social, de que, nas palavras de Emílio José Loureiro, "o alcoolismo crônico lavra entre nós", ou nas de Caetano Antônio Azevedo que ele está "tão espalhado em nossos dias". ${ }^{23}$ E por qual motivo? Segundo este último médico: "Em uns é o apetite particular para as bebidas espirituosas que os arrasta aos excessos cotidianos. Em outros é a ociosidade." As mazelas da vida também podem levar as pessoas a se entregarem a esse mal, razão pela qual, para ele, "na classe operária convida-se a beber a toda a hora do dia", porque nela a bebida funciona como "um consolador

${ }^{19}$ AZEVEDO, Caetano Antônio. Do alcoolismo crônico e suas conseqüências. Rio de Janeiro: Faculdade de Medicina do Rio de Janeiro, 1839, p. 3.

${ }^{20} \mathrm{RUSH}$, Benjamin. Inquiry in to effects oh ardent spirits upon the human body and mind. Filadelfia: Benjamin \& Thomas Kite publishers, 1816.

${ }^{21}$ SANTOS, Alcoolismo: a invenção de uma doença..., p. 86.

${ }^{22}$ BRAGA, José Simplício Monteiro. Do alcoolismo crônico... Rio de Janeiro: Faculdade de Medicina do Rio de Janeiro, 1883, p. 48.

${ }^{23}$ LOUREIRO, Emílio José. Do alcoolismo crônico e suas conseqüências. Rio de Janeiro: Faculdade de Medicina do Rio de Janeiro, 1884, p. 4 e AZEVEDO, Do alcoolismo crônico..., p. 3. 
que faz esquecer os pesares." Por isso, adverte outro médico, Mathias Vilhena, sabendo-se que seu "serviço é mal remunerado e cuja alimentação é deficiente, as bebidas alcoólicas em vez de úteis são prejudiciais." 24

Essa advertência está ligada ao fato de que fazia parte dos costumes do país dar pequenas porções de aguardente aos trabalhadores ao longo do dia, principalmente nas frentes de trabalho manuais do imenso espaço rural brasileiro, para servir como estimulante capaz de animar os indivíduos, a maioria ainda submetida à escravidão, a superar a árduas e longas jornadas de trabalho.

Assim generalizava-se a visão de que o vício de ingerir álcool frequentemente e em demasia estava disseminado pelo tecido social em como tal, devia ser combatido em nome do progresso do país.

Dito isso é necessário mostrar que realmente havia nos escritos médicos sobre esse assunto uma clara consciência da necessidade de combater o alcoolismo. Por exemplo, Mathias Antonio Moinhos Vilhena, em sua tese intitulada Do uso e abuso de bebidas alcoólicas, publicada em 1882, afirma que "para o reprimir, é importante a intervenção do governo". Além disso, tendo como referência o "exemplo dos norteamericanos" sugere que se fundem sociedades cujos "sócios, que sobre o povo podem exercer influência pela posição que ocupam e pela reconhecida ilustração, incumbem-se de em conferências públicas fazer a propaganda contra o álcool". ${ }^{25}$

As razões pelas quais tal combate deveria ser travado já foram reveladas por Fernando dos Santos, segundo o qual o capitalismo exigia que a energia dos trabalhadores fosse preservada (disciplinarizada) para a maximização da produção, o que levou à reinvenção da tradição de beber em excesso, isto é, transformou um hábito tolerável em uma doença. Afinal, como outro estudo reafirma em relação ao Brasil: "O consumo de bebidas alcoólicas pelas elites coloniais não era da mesma forma repreensível. Ao contrário, seu emprego, além das festas e relações sociais era considerado medicinal, de forma coerente com as teorias miasmática e humoral que orientavam o saber médico de então" ${ }^{26} \mathrm{O}$ mesmo também pode ser dito para outras experiências históricas, segundo autores que se dedicaram a esse assunto em outros países, os quais mostram como a população em geral lidava com o álcool antes das relações de produção assalariadas se consolidarem, enfatizando a atitude tolerável das elites, tanto a médica, quanto a governamental, em relação à utilização dessa substância, inclusive no que diz respeito à sua ingestão exagerada em bebidas. ${ }^{27}$

\footnotetext{
${ }^{24}$ AZEVEDO, Do alcoolismo crônico..., p. 3 e VILHENA, Mathias Antonio Moinhos. Do uso e abuso de bebidas alcoólicas. Rio de Janeiro: Tipografia de J. D. Oliveira, 1882, p. 25.

${ }^{25}$ VILHENA, Do uso e abuso de bebidas alcoólicas..., respectivamente p. 4 e p. 63 .

${ }^{26}$ ACSELRAD, Gilberta. Relatório de pesquisa: Consumo de bebidas alcoólicas no Brasil. Rio de Janeiro: 2012. p. 87.

27 FERNÁNDEZ Jorge Sánchez Mejorada. "Concepto del alcoholismo como enfermedad". Revista Médica, vol. 7, n. 1, 2007; LEVINE, Harry G. e REINARMAN, Craig. Alcohol prohibition and drug prohibition. Lessons from alcohol policy for drug policy. Amsterdam: CEDRO, 2004; CAMPOS, Ricardo Marín. Alcoholismo, medicina y sociedad en España (1876-1923). Madrid: CSIC, 1997; QUÉTEL, Claude e SIMON, Jean-Yves. "L'aliénation alcoolique en France (XIXe siècle et 1ère moitié du XXe siècle)". Histoire, économie et société. Année 1988, vol. 7, n. 4, p. 507-53; SOUNRIA, Jean Charle. Histoire de L'Alcoolisme. Paris, Flamarion, 1986. MARRUS, Michael R. "Social Drinking in the Belle Epoque". Journal of Social History, vol. 7, n. 2, 1974, p. 115-141.
} 
Aos poucos, com a ascensão do capitalismo, de acordo com Fernando dos Santos, "a nova tradição de uso dos alcoólicos que a medicina tentou implantar mudou o sentido do consumo destas bebidas, tirando-as das esferas do ritual e da cura, $e$ mantendo apenas a face do prazer, originalmente ligado às festas" ${ }^{28}$ Assim, a sensibilidade, ou a maneira de perceber o hábito de consumir bebidas alcoólicas, foi sendo modificada. Os textos das elites médicas em todo o Ocidente revelam isso. ${ }^{29}$ Neles encontram-se diversas passagens em que seus autores detratam, deploram, condenam, etc., tal hábito. Por exemplo, Alexandre José do Rosário, já em 1839, um dos primeiros a abordar esse tema, na sua tese $A$ influência dos alimentos e bebidas sobre a moral dos homens afirma que, sob efeito do álcool, "os homens tornam-se capazes de cometer as mais revoltantes violências," ao ponto de nadar mais poder conter as "suas desordenadas paixões," levando-o à "degradação completa da moral" ${ }^{30}$

Essa condenação foi reiterada exaustivamente nos escritos médicos ao longo do século XIX, como no de Matheus Vilhena, no qual reforça o argumento de que durante a embriaguês "o caráter sofre modificações sensíveis, de modo que "o homem embriagado não obedece a deveres e nem a imposições sociais" $e$ "ainda pode cometer atos vergonhosos e crimes" ${ }^{31}$

A mesma ponderação e de forma mais contundente fez José Cupertino Teixeira Fontes em Do alcoolismo crônico e suas conseqüências, no qual diz:

O alcoolismo degrada o indivíduo fazendo-o perder os hábitos de trabalho regular, arruinando a sua inteligência $e$ sua força, obrigando-o a sacrificar a sua família para ter o que beber, torna-o imoral, destrói os laços conjugais e, finalmente, o reduz à miséria com seu cortejo de sofrimentos físicos e morais, embrutecendo-o e o obrigando a todas as espécies de crimes. ${ }^{32}$

Essa percepção perpassa todos os textos médicos da segunda metade do século XIX que condenam o uso rotineiro e exagerado de bebidas alcoólicas. Para seus autores, a grande preocupação é o fato de, segundo eles, "o alcoolismo, sob o ponto de vista moral, corrompe, degrada e embrutece; sob o ponto de vista físico, ataca os órgãos $e$ as funções principais do organismo; em relação à espécie, a degrada $e$ esteriliza" ${ }^{33}$ o que poderia afetar o progresso; idéia que se tornou uma obsessão nos meios intelectuais desde a Ilustração.

\footnotetext{
${ }^{28}$ SANTOS, Alcoolismo: a invenção de uma doença..., p. 7.

29 LEVINE e REINARMAN, Alcohol prohibition and drug prohibition.... CAMPOS, Alcoholismo, medicina y sociedad en España (1876-1923)...; QUÉTEL e SIMON, "L'aliénation alcoolique en France"...; SOUNRIA, Histoire de L'Alcoolisme....

${ }^{30}$ ROSÁRIO, Alexandre José do. A influência dos alimentos e bebidas sobre a moral dos homens. Rio de Janeiro: Faculdade de Medicina do Rio de Janeiro, 1839, p. 37.

${ }^{31}$ VILHENA, Do uso e abuso de bebidas alcoólicas..., p. 31.

${ }^{32}$ FONTES, José Cupertino Teixeira. Do alcoolismo crônico e suas conseqüências. Rio de Janeiro: Faculdade de Medicina do Rio de Janeiro, 1884, p. 89.

${ }^{33}$ FONTES, Do alcoolismo crônico e suas consequências..., p. 89.
} 
Tal ideia é essencial para a compreensão dos textos médicos que propuseram o combate ao alcoolismo, motivo pelo qual a seguir será feita uma breve exposição do seu conceito, pois a partir dele foi criada ideologia do progresso, ${ }^{34}$ que teve ampla repercussão na época, e é com base nela que poderemos compreender as posições ideológicas dos autores, engajados no referido combate, diante dos problemas causados pelo consumo exagerado e rotineiro de bebidas alcoólicas.

Para John Bury, a idéia de progresso está associada com a interpretação filosófica de que a história é determinada pela caminhada inexorável dos povos para um futuro melhor. Tal associação ganhou força a partir da segunda metade do século XVIII, quando vários escritores, sobretudo Turgot, estabeleceram que o nível cultural $e$ material das sociedades deve ser usado como critério de avaliação do avanço da civilização, segundo Robert Nisbet. Dessa forma, apesar da divergência entre esses autores em torno da idéia de progresso, pois o primeiro a vê como um instrumento político de imposição de uma visão de mundo e o segundo como um elemento inerente ao avanço dos povos, ambos concordam que a partir da Ilustração ela passou a ser considerada uma idéia fundamental para a compreensão das sociedades ocidentais nos seus mais diversos aspectos (arte, filosofia, ciência, etc.). ${ }^{35}$

Assim, como conceito, na Enciclopédia de Denis Diderot e Jean d'Alembert, progresso "significa marcha para frente" e designa na linguagem filosófica a caminhada do gênero humano para a sua perfeição $e$ felicidade ${ }^{36}$ Com esse mesmo significado, ele é apresentado no Grande Dicionário Universal do Século XIX como um conjunto de conquistas, a vitória "da civilização sobre a barbárie, da ciência sobre a ignorância, da liberdade sobre o despotismo, da riqueza sobre a miséria e do bem sobre o mal", ${ }^{37}$ que impulsiona a humanidade para uma época promissora.

Compreendida dessa maneira, a idéia de progresso foi consolidada ao longo do século XIX, sendo a publicação da Origem das espécies de Charles Darwin em 1859 (que transformou a evolução em uma noção essencial para a compreensão da vida) um marco da sua consolidação. ${ }^{38}$ Após esse marco, conforme afirmação do autor do artigo sobre tal idéia inserido no Grande Dicionário Universal do Século XIX, "a fé na lei do progresso tornou-se a fé da nossa época", pois "trata-se de uma crença, que encontra poucos incrédulos", de que "o progresso é a lei da marcha do gênero humano". ${ }^{39}$

\footnotetext{
${ }^{34}$ Expressão usada por DUPAS, O Mito do progresso..., p. 23 ao explicar que a idéia de progresso foi transformada em ideologia para sustentar opções políticas da elite intelectual e governamental no Ocidente a partir da Ilustração, usando para isso o conceito de ideologia ("visões sintéticas e fragmentárias, elípticas, coerentes na aparência, que engendram o sentido social da ação") formulado por Raymondo Mier no seu texto homônimo inserido na obra, organizada por Laura Baça Bokserliwerant et al, intitulada Léxico de la poíitica. Ciudad del México, Facultad Latinoamericana de Ciencias Sociais, 2000, p. 323.

${ }^{35}$ BURY, John. The idea of progress. Honolulu: University Press of the Pacific, 2004 e NISBET, Robert. History of idea of progress. New York: Basic Books, 1980.

${ }^{36}$ Diderot, Denis e d'Alembert, Jean. Encyclopédie ou dictionnaire raisonné des sciences, des arts et métiers. Tome I, Lucques, Chez Vicent Giuntini, p. 347, 1758.

${ }^{37}$ LAROUSSE, Pierre. Grand dictionnaire universel $d u$ XIX siècle. Paris: Administration du grand Dictionnaire universel, 1875.

${ }^{38}$ VALADE, Bernard. Idée de progrés. Encyclopaedia universalis, 2004.

${ }^{39}$ LAROUSSE, Grand dictionnaire universel du XIX siècle....
} 
Concebida dessa maneira, essa ideia fundamentou o ideário reformista das elites médicas do Ocidente, incluindo as que aturam no Brasil na época do Império, as quais, em nome dela, propuseram o combate aos costumes que, na sua visão, provocavam inúmeras doenças e, consequentemente, agravava o quadro sanitário travando a marcha do progresso.

Um dos autores de uma das mais extensas teses a respeito do uso e abuso das bebidas alcoólicas, Mathias Vilhena, depois de expor diversas pesquisas sobre esse tema, principalmente as produzidas nos Estados Unidos e na Europa, particularmente na Alemanha e na França, e reafirmar que "a influência do alcoolismo sobre as populações e as raças humanas é um problema delicado", por afetar o caráter dos indivíduos, a sua saúde, a sua reprodução, o seu trabalho a sua família, a sociedade e a própria espécie, adverte: "O alcoolismo é um óbice ao progresso." Tanto que, segundo ele, essa doença "é considerada na Europa como uma calamidade social, um agente que destrói e tende a aniquilar as forças produtivas das nações". Por essa razão, ele insiste que o costume de se consumir bebidas alcoólicas diariamente e em excesso "deve ser condenado pelo médico e coibido por aqueles aos quais a direção da sociedade está entregue." Mais do que isso, o "triste cortejo" gerado no tecido social por causa do consumo imoderado de tais bebidas "dá o direito a uma intervenção direta com o fim de o coibir a todo aquele que se esforça pelo bem estar da humanidade". ${ }^{40}$

Em outras palavras, "o alcoolismo é uma das grandes causas da despovoação e da decadência das nações," razão pela qual "susta a marcha ascendente da humanidade e a conduz ao abismo da degradação, conforme palavras de José Simplício Monteiro Braga, outro médico que procurou mostrar o quanto esse "mal social" poderia comprometer o progresso nacional. ${ }^{41}$

Então percebe-se que conceitos essenciais dos alicerces intelectuais do Iluminismo serviram como fundamento ideológico para a construção de um ideário médico reformista, a partir do qual seus promotores propuseram o combate às más condições de saúde do país, gerada por uma infinidade de doenças, como o alcoolismo, provocadas pelo o que os médicos da época chamavam de "funestos hábitos". ${ }^{2}$

Sendo assim, além da disciplinarização dos corpos para preservar as energias dos indivíduos para a maximização do trabalho, levando a "reinvenção da tradição" de beber transformada de bebedeira em alcoolismo, tese proposta por Fernando dos Santos, deve-se levar em conta também o fato de que, para embasar seus argumentos e torná-los aprioristicamente legítimos, os autores brasileiros de textos médicos que pregaram a necessidade de combater o alcoolismo valeram-se, como seus pares ocidentais, de conceitos centrais da tradição intelectual ilustrada, sobretudo o de progresso.

\section{$\operatorname{soc}$}

${ }^{40}$ VLHENA, Do uso e abuso de bebidas alcoólicas...., respectivamente p. 60-61, 58, 60 e 62 .

${ }^{41}$ BRAGA, José Simplício Monteiro. Do alcoolismo crônico... Rio de Janeiro: Faculdade de Medicina do Rio de Janeiro, 1883, p. 48.

${ }^{42}$ FONTES, Do alcoolismo crônico e suas consequências..., p. 89. 


\section{RESUMO}

A partir do final do XVIII, no Ocidente, o hábito de consumir bebidas alcoólicas em excessivo $e$ regularmente começou a ser visto por uma parte das elites intelectuais, principalmente a identificada dos ideais da Ilustração, como um problema social. A partir daí, aos poucos, diversos setores da sociedade que foram influenciados pelo pensamento ilustrado, em particular os da área médica, começaram a combater tal hábito produzindo textos mostrando os males do alcoolismo para o indivíduo e sociedade. Neste artigo será analisado como esse combate foi iniciado no Brasil do século XIX, com o objetivo de conhecer as motivações dos que o levaram a cabo e como estes fundamentaram intelectualmente o seu empenho. Para isso, serão utilizadas as teses médicas defendidas na Faculdade de Medicina do Rio de Janeiro à luz da bibliografia especializada no assunto, as quais serão interpretadas com base no conceito de cultura formulado por Peter Burke e no conceito de campo formulado por Pierre Bourdieu, para mostrar que neste país membros da sua elite médica também se engajaram naquele combate $e$, com isso, acabaram contribuindo para começar a colocar o enfrentamento ao vício do consumo de bebidas alcoólicas na agenda pública nacional.

Palavras Chave: Combate médico; Alcoolismo; Saúde Pública; Progresso.
ABSTRACT
From thelate eighteenth century, in the West, the habit of consuming alcoholic beverages in excessive and regularly began to be seen by a part of the intellectual elites, mainly the one identified of the ideals of the Illustration, as a social problem. From then on, various sectors of society that were influenced by enlightened thinking, in particular those in the medical field, began to combat this habit by producing texts showing the evils of alcoholism for the individual and society. This article will analyze how this combat was started in Brazil in the 19th century, with the objective of knowing the motivations of those who carried it out and how these intellectually grounded their commitment. For this, the medical theses defended at the Faculty of Medicine of Rio de Janeiro will be used in the light of the bibliography specialized in the subject, which will be interpreted based on the concept of culture formulated by Peter Burke and in the concept of field formulated by Pierre Bourdieu, for show that in this country members of their medical elite also engaged in that fight and, with that, they ended up contributing to begin to put the confrontation to the addiction of the consumption of alcoholic beverages in the national public agenda.

Keywords: Medical combat; Alcoholism; Public health; Progress.

Artigo recebido em 04 jan. 2017.

Aprovado em 12 fev. 2017. 